www.periodicos.unimontes.br/index.php/caminhosdahistoria

\title{
BELO HORIZONTE, A CIDADE MODELAR: REPRESENTAÇÕES DA NOVA CAPITAL DAS MINAS GERAIS
}

\author{
Rogério Othon Teixeira Alves ${ }^{1}$
}

Recebido em: 25/04/2020 Aprovado em: 08/06/2020

\begin{abstract}
Resumo: Ao se fundar a moderna cidade de Belo Horizonte em 1897, a sua dinâmica revelaria significados que extrapolariam a prancheta dos engenheiros. Com o tempo, aspectos políticos e sociais que forjariam aquela sociedade seriam trazidos nos periódicos da época da nova capital. Quais os sentimentos primários ao se pensar na nova cidade? Havia ideais políticos nela embutidos? Quais as reações e tensões refletidas da antiga capital, Ouro Preto? Quem foram os primeiros belo-horizontinos? Este trabalho buscou em periódicos mineiros, informações que demonstrassem a ideia da construção na nova capital e os desdobramentos decorridos da nova sociedade. A fundação da cidade refletiria supostamente o moderno, o civilizado, o urbano, em contraposição à antiga e atrasada Ouro Preto monarquista. Pelos periódicos e autores consultados, percebeu-se que na mudança de endereço da capital não havia intuito de se negligenciar o orgulho do povo mineiro, depositado nas ideias libertárias dos personagens independentistas da Ouro Preto oitocentista. Se, em princípio, no reino ideológico o objetivo foi sepultar a antiga Ouro Preto embaixo da arrojada Belo Horizonte, na prática, o sujeito que se formava na nova capital, orgulhou-se da grandiosa moderna cidade sem desmerecer o passado, a tradição e a história da antiga.
\end{abstract}

Palavras-chave: História; Modernidade; Capital; Belo Horizonte; Ouro Preto.

\section{BELO HORIZONTE, LA CIUDAD MODELO: REPRESENTACIONES DE LA NUEVA CAPITAL DE MINAS GERAIS}

Resumen: Cuando se fundó la moderna ciudad de Belo Horizonte en 1897, su dinámica revelaría significados que extrapolarían el tablero de dibujo de los ingenieros. Con el tiempo, los aspectos políticos y sociales que forjarían esa sociedad aparecerían en las publicaciones periódicas de la época de la nueva capital. ¿Cuáles son los sentimientos principales al pensar en la nueva ciudad? ¿Había ideales políticos incorporados? ¿Cuáles son las reacciones y tensiones reflejadas en la antigua capital, Ouro Preto? ¿Quiénes fueron los primeros habitantes de Belo Horizonte? Este trabajo buscó en publicaciones periódicas de Minas Gerais, información que demostrara la idea de la construcción en la nueva capital y los desarrollos que resultaron de la nueva sociedad. La fundación de la ciudad supuestamente reflejaría lo moderno, lo civilizado, lo urbano, en oposición al antiguo y atrasado monárquico Ouro Preto. A partir de las publicaciones periódicas y los autores consultados, se observó que en el cambio de domicilio en la capital, no había intención de descuidar el orgullo del pueblo de Minas Gerais, depositado en las ideas libertarias de los personajes independentistas de Ouro Preto del siglo XIX. Si, en principio, en el ámbito ideológico el objetivo era enterrar al viejo Ouro Preto bajo el atrevido Belo Horizonte, en la práctica, el sujeto que se formó en la

\footnotetext{
${ }^{1}$ Doutor em Estudos do Lazer. Professor do Departamento de Educação Física e do Desporto, Coordenador do Ludens - Grupo de Estudo e Pesquisa do Lazer. Universidade Estadual de Montes Claros-MG, Brasil. Email: rogerioothon@gmail.com. ORCID: https://orcid.org/0000-0002-4023-726X.
} 
nueva capital, estaba orgulloso de la gran ciudad moderna sin menospreciar el pasado y la historia de la antigua.

Palabras clave: Historia; Modernidad; Capital; Belo Horizonte; Ouro Preto.

\title{
BELO HORIZONTE, THE MODEL CITY: REPRESENTATIONS OF THE NEW CAPITAL OF MINAS GERAIS
}

\begin{abstract}
When the modern city of Belo Horizonte was founded in 1897, its dynamics would reveal meanings that would extrapolate the engineers' drawing board. What are the primary feelings when thinking about the new city? Were there political ideals built into it? What are the reactions and tensions reflected in the old capital, Ouro Preto? Who were the first Belo Horizonte people? This work sought, in periodicals from Minas Gerais, for information that demonstrated the idea of construction in the new capital and the developments that resulted from the new society. From the periodicals and authors consulted, it was noticed that in the change of address in the capital, there was no intention of neglecting the pride of the people of Minas Gerais, deposited in the libertarian ideas of the 19th century Ouro Preto independenceist characters. If, in principle, in the ideological realm the objective was to bury the old Ouro Preto under the bold Belo Horizonte, in practice, the person who was formed in the new capital, prided himself on the great modern city without belittling the past, the tradition and the history of the old one.
\end{abstract}

Keywords: History; Modernity; Capital; Belo Horizonte; Ouro Preto.

\section{Introdução}

Avançar nos estudos do contexto histórico da fundação da cidade de Belo Horizonte é desafiador, devido, principalmente, à quantidade de autores que já se debruçaram sobre a temática. Em mais de cem anos de fundação, diversos trabalhos foram desenvolvidos sobre a cidade $^{2}$, mas, conjectura-se que o esgotamento dos "olhares" históricos seja algo incomum e seguramente sempre haverá nuances a serem buriladas sobre o tempo e o espaço de Belo Horizonte em qualquer época.

Neste estudo, a ênfase será o que engendrou a cidade considerando-a um pequeno espaço, acompanhando uma tendência de estudos históricos formulados nos anos 1950 e que ficaram conhecidos como história local. Nas análises possíveis, considerou-se o local geográfico (micro-espaço), que abrigou e forjou o sujeito belo-horizontino. Sem embargos, estudar a Belo Horizonte do início do Século XX, é lidar com um estilo de história local que:

[...] surgia precisamente como a possibilidade de oferecer uma iluminação em detalhe de grandes questões econômicas, políticas, sociais e culturais que

\footnotetext{
${ }^{2}$ A título de conhecimento e marco acadêmico, em 1997, ano do centenário de fundação de Belo Horizonte, foram publicados textos científicos sobre a história da cidade, estudos resultantes do simpósio "Belo Horizonte: tempo, espaço e memória", que ajudaram na compreensão de diversos aspectos da nova capital de Minas Gerais, como a idealização, concepção e o desenvolvimento durante o Século XX. (Revista Cadernos de História Número Especial, Belo Horizonte: PUC-Minas, v. 2, n. 3, p. 1-100, out. 1997)
} 
até então haviam sido examinadas no âmbito das dimensões nacionais (BARROS, 2006, p. 470).

Nesse contexto, perceber a história regional da construção da atual cidade de Belo Horizonte, capital do estado de Minas Gerais, no final do Século XIX e início do Brasil como República, requereu clarear o que se denominou historicamente como modernidade, desdobramentos da Revolução Industrial iniciada na Inglaterra do Século XVIII.

A modernidade, período que determinou uma nova realidade social que vigoraria no mundo em cada tempo e espaço, respeitados os ritmos e as possibilidades de cada localidade, "[...] refere-se a estilo, costume de vida ou organização social que emergiram na Europa a partir do século XVII e que ulteriormente se tornaram mais ou menos mundiais em sua influência” (GIDDENS, 1991, p.11). No Brasil não seria diferente.

No tocante à Belo Horizonte, para além da construção propriamente dita, é importante absorver as ideias do projeto da nova capital e como o povo, que nela se instalaria, deveria portar-se diante de uma nova estrutura física e social, emoldurada em ideais de modernidade, porém, ao mesmo tempo, atrasada e arcaica. Assim, ao se fundar a cidade em 1897, a sua dinâmica revelaria significados que extrapolaram a prancheta dos engenheiros, pois aspectos políticos e sociais que forjariam aquela sociedade seriam trazidos rotineiramente nos periódicos da época da nova capital. Como bem expôs Passos (2016, p.334):

[...] é necessário ter em mente que o projeto da cidade e as medidas tomadas para sua completa implantação devem ser entendidos dentro do seu tempo, numa visão de valorização do racional e para uma capital que se pretendia modelo dentro do "Estado republicano".

Considerando a imprensa e os pesquisadores que já estudaram a história da cidade, foi possível questionar-se: Quais os sentimentos primários ao se pensar na nova cidade? Havia ideais políticos nela embutidos? Quais as reações e tensões refletidas da antiga capital, Ouro Preto? Quem foram os primeiros belo-horizontinos? Diante desses questionamentos, este trabalho buscou em periódicos mineiros do final do Século XIX e início do Século XX, informações que demonstrassem a ideia da construção na nova capital de Minas Gerais e os desdobramentos decorridos da nova sociedade.

Para alcançar os objetivos propostos, foi necessário acessar periódicos encontrados no Arquivo da Imprensa Oficial do Estado de Minas Gerais, na Coleção Linhares da Universidade Federal de Minas Gerais (digitalizada e acessada via internet) e na Hemeroteca Histórica da Biblioteca Pública Luiz de Bessa. Todos localizados em Belo Horizonte. Importante frisar que a imprensa de Belo Horizonte nasceu antes mesmo da cidade ser 
fundada, sendo "[...] produzida de forma artesanal e improvisada numa tipografia no fundo da igreja local" (RODRIGUES, 2016, p.106) desde o ano de 1895 e, em função do período pesquisado, neste artigo, ao serem citados textos dos jornais da época foi respeitada a grafia portuguesa do momento. Enfim, para alcançar os objetivos propostos, além das fontes jornalísticas, textos científicos como dissertações, teses e artigos, também subsidiaram o entendimento e a análise das informações.

\section{As primeiras ideias e representações da nova cidade}

A procura por um local de construção da nova capital do estado de Minas Gerais seguiu inúmeros critérios $^{3}$, mas a escolha de um povoado denominado Curral d'El Rei, à época, aproximou-se de uma forma de os republicanos demonstrarem domínio da situação no País e acabar com os resquícios da monarquia. Desta forma, o principal critério para a escolha do local da nova cidade seria o político (RODRIGUES, 2016).

Pelo Decreto n.1.085, de 12 de dezembro de 1897, inaugurou-se oficialmente a nova capital com o nome de Cidade de Minas. Em 1901, passou a ser chamada oficialmente Bello Horizonte (VERIANO, 2001). Na primeira alvorada da Capital, “[...] a cidade embrionária amanheceu toda embandeirada e em clima de festa, afinal era a primeira cidade republicana planejada que ganhava vida e mostrava que o futuro estava por aí, bem à nossa frente" (COSTA; SCHWARCZ, 2007, p.43).

O primeiro jornal da cidade, o Bello Horizonte ${ }^{4}$, ainda antes da fundação oficial, descreve, em 1896, a suposta aspiração republicana da localidade escolhida para abrigar a nova capital. Na bravia "Curral d'El-Rei quando as questões políticas tocavam ao extremo,

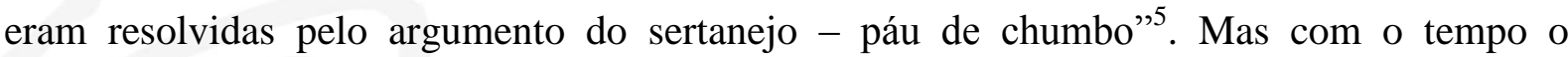
nervosismo político foi se arrefecendo, e "nos últimos dias da monarchia, foram aqui levantados em plena rua os sediciosos gritos de - Viva a República!” Quando se mudou de “Curral d'El Rei para Bello Horizonte, era para apagar de vez tudo que a trono cheirasse ou a rei se referisse".

\footnotetext{
3 “Em 28 de outubro de 1891, foi promulgada a Lei nº 1 , adicional à Constituição de Minas Gerais, determinando o estudo das seguintes localidades para que, dentre elas, fosse escolhida aquela destinada à capital do Estado: Belo Horizonte, Paraúna, Barbacena, Várzea do Marçal e Juiz de fora. A 17 de dezembro de 1893, o Presidente do Estado Chrispim Jacques Bias Fortes, promulgou a Lei n³, adicional à Constituição do Estado, decidindo pela localidade de Belo Horizonte para construção da nova Capital” (VERIANO, 2001, p. 58-59).

${ }^{4}$ Bello Horizonte. Domingo, 2 de fevereiro de 1896. Traços historicos e descriptivos de Bello Horizonte V, p.1.

5 A expressão páu de chumbo simboliza a indolência do povo da localidade para com os desmandos da monarquia, algumas decisões políticas eram resolvidas à maneira local, no enfrentamento corporal, nas armas.
} 
Em artigo científico, Fernando Lara analisou as transformações do espaço urbano de Belo Horizonte a partir da narrativa memorialista-ficcional do escritor juiz-forano Pedro Nava nos anos 1921 a 1926, em seu terceiro livro de memórias, intitulado Beira-Mar, e definiu: "Belo Horizonte não foi feita para lembrar, mas foi feita para esquecer" (LARA, 1998, p.96). A cidade é fruto do Brasil republicano, "troféu" dos defensores do recém-instalado regime de governo brasileiro em 1889. A monarquia, representada em Minas Gerais pelas estreitas e tortuosas ruas de Ouro Preto, deu lugar à pretendida e presunçosa democracia da República. Nesse cenário, ergueu-se o símbolo da modernidade, a Paris ao sul da linha do equador, dadivosa de linhas retas, e que não seria apenas símbolo da mudança no plano físico. Como expos Vilhena (2008), no plano simbólico, a construção da nova cidade transcendia ideais políticos e com o uso do concreto armado se consolidaria a representação de um novo poder imbuído de novos ideais.

Em 1906, a primeira edição do Annuario de Minas Geraes ${ }^{6}$, documento oficial do Estado, publicou informações que exaltava os aspectos modernos e a perfeição da nova capital, onde "[...] todos a proclamam de belleza e plano sem egual, em terra sul-americana. Hygiene, policia, architectura, salubridade, paizagem, arborisação, estylo, ventilação, luz, espaço, conforto - tudo nessa se encontra, abundantemente”. Ela “[...] é a bella e moderna cidade de Bello Horizonte, cidade edificada com rapidez e audacia yankes, dignas do nobre e energico povo Mineiro, custou ao Thesouro do Estado rs. 33.073:000\$000”. A cidade trazia características que refletiam civilidade, urbanidade e desenvolvimento que antes não se notavam.

Rodrigues (2006) expõe que, na sua idealização, se projetou o que de mais atual e moderno havia do urbanismo e, seguindo essa visão, ela foi erigida:

[...] como cidade onírica, Belo Horizonte foi idealizada com um traçado urbano que seguia um esquema do urbanismo em voga na época, pois o sonho utópico era estabelecer a civilização e a tecnologia avançada do mundo moderno. Nesse sentido, a planta da cidade foi inspirada em grandes projetos urbanísticos do século XIX, como Paris, de Haussmann; Washinton D. C., de L'Enfant; e La Plata" (RODRIGUES, 2006, p.41).

Adentrando o Século XX, o jornal A Gazeta", de 1923, se orgulhou da "Bello Horizonte moderna, moldada pela esthetica mais apurada e uma das unicas cidades" puramente "brasileira, construida por brasileiros, após a independencia do paiz". Segundo o jornal, podia-se observar a "preocupação que presidiu a sua construção", arquitetada com o

\footnotetext{
${ }^{6}$ Annuario de Minas Geraes. Bello Horizonte, 1906, p.131.

${ }^{7}$ A Gazeta. Segunda-feira, 28 de maio de 1923: Aspectos da cidade, p.2.
} 
que de mais atual havia na engenharia. Mesmo que houvesse críticos repreendendo a sua imagem, "ella é, assim, linda no seu aspecto bizarro". Sentiu-se, na sua construção, "a preocupação em dar-nos uma cidade modelar".

À época, o poder regional no Brasil, analisa Sevcenko (1992, p.14), "representado principalmente pelos ricos fazendeiros de café do Sudeste pretendia que com a República fosse implantado o sistema federalista, assegurando-lhes não só o controle dos seus próprios rendimentos quanto condições de usar seu poder econômico para decidir os destinos da futura ordem republicana". Dessa forma, não mais se ficaria aos auspícios da centralizadora Capital Federal. Seguindo esse preceito, o estado de Minas Gerais impôs sua soberania planejando e construindo uma nova capital, de ares modernistas.

Tal mudança literal e relativa não poderia, porém, sepultar o passado e as cultivadas tradições mineiras, marcado pelo movimento de Inconfidência Mineira e que teve como palco principal a pujante Ouro Preto de outrora. Por isso, o traslado do funcionalismo público estadual da antiga Capital para a nova não foi um movimento sem sentido, como explica Thais Velloso Pimentel:

E assim surgiu Belo Horizonte. A cidade que pretendeu ser, ao mesmo tempo, um atestado da modernidade dos mineiros que procuravam se adequar aos novos ventos republicanos, e a guardiã das tradições tão importantes na história desse povo. Como adequar as duas perspectivas? Simples. A cidade, moderna na sua forma, deveria acolher, no seu conteúdo, uma população cônscia do valor da tradição mineira. Moradores de Ouro Preto seriam transferidos para Belo Horizonte, garantindo a perpetuação dos valores já vivenciados na antiga Capital (PIMENTEL, 1989, p.23).

Não havia intuito, na mudança de endereço da Capital, de se negligenciar o orgulho do povo mineiro, depositado nas ideias libertárias dos personagens independentistas da Ouro Preto oitocentista. Se a grandiosidade e arrojo da novata Belo Horizonte enchiam os olhos pela beleza, vastidão e saúde, a saudade, o passado, a tradição e a história se faziam inabaláveis na alma da antiga e gloriosa metrópole que foi Villa Rica e, depois, Ouro Preto.

Notamos essa bifurcação, ou mesmo tensão, de valores anunciada pelo jornal $A$ Faísca $^{8}$ no ano de 1916: "Bello Horizonte symbolisa o nosso vigor actual, de povo que vibra e espera a nova capital, é o signal de nossa futurosa industria e commercio". Já a "velha metrópole", Ouro Preto, "[...] definha pacientemente e lembra as nossas glorias de um passado que foi longo e brilhante pelos feitos de nossos maiores e pelos faustos que constituíram o sublime apogeu de Minas no século dezoito". A Faísca ainda indica que Belo Horizonte “[...] terá de ser uma das maiores e mais ricas capitaes de nossa Patria", porque,

\footnotetext{
${ }^{8}$ A Faísca. Terça-feira, 12 de dezembro de 1916: A nova capital de Minas, p.1.
} 
Ouro Preto, "[...] já foi o melhor, mais rico e mais admirável centro intellectual, de todo Brazil, ao findar do século de 1700”. A nova capital nascia, segundo o periódico, com a responsabilidade de trabalhar e honrar o passado da antiga: "Olhemos para o futuro, Bello Horizonte honrará Ouro Preto".

O projeto da nova metrópole do estado de Minas Gerais era, porém, arrojado demais para o povo que aqui viveria, principalmente levando-se em conta que a maioria da população foi proveniente da zona rural, bem diferente de Paris, ou mesmo da alta classe do Rio de Janeiro. A alcunha modernista ${ }^{9}$ para Belo Horizonte não seria algo fácil de implantar. $\mathrm{O}$ itabirano Carlos Drummond de Andrade sintetiza num verso essa confusão, quando se viu de frente com o pretenso aspecto moderno da nova Capital mineira. A sensação de "ser-não-sermoderno" acompanharia o jovem poeta por toda a sua vida. No elevador penso na roça, na roça penso no elevador ${ }^{10}$.

Assim como Drummond, Cyro do Anjos, outro literato do interior de Minas Gerias, mais precisamente da cidade de Montes Claros - Norte de Minas, também narrou o surgimento da modernidade de Belo Horizonte através do verso e da prosa, representando suas ruas e o que acontecia nelas. Segundo Marcia Senra (2011), Drummond e Cyro dos Anjos:

Por meio de uma linguagem poética, metaforizada, mediada pela vivência, pela paixão e pelo desejo desses escritores / leitores que percorreram suas ruas, pode-se entrever a cultura da modernidade. Cultura esta, que é eminentemente urbana e marcada pelas imagens da constante transformação, fugacidade, artificialidade, inautenticidade, contrastes e fragmentação; enfim, imagens ambivalentes. Mas não se pode olvidar que a cidade é onde as coisas acontecem e, a metrópole, é a forma mais específica de realização da vida moderna (SENRA, 2011, p.78).

\section{Moderno e tradicional: uma convivência possível}

O processo de urbanização do Brasil, segundo Silveira e Silva (2010), é um fenômeno recente, se considerarmos que, no início do século XX, menos de $10 \%$ dos brasileiros viviam nas cidades. A partir da lógica capitalista, o Brasil iniciou nesse período seu processo de industrialização, e as cidades começaram a crescer de maneira acelerada e desorganizada. Simão (2008) elucida o período dizendo que junto com um discurso republicano, que evocava

\footnotetext{
${ }^{9}$ Oliven (2001) expõe que o Brasil tendeu a importar as ideias e modelos vigentes da Europa entendendo que aderir a tudo que está em voga nos lugares adiantados seria moderno. Mas esse modernismo brasileiro no século XIX se restringia à alta-classe do Rio de Janeiro, o resto do país era rural, de economia agrária. Sendo o urbanismo condição para evolução social, o Brasil demoraria a sair da condição de semicolonial agrário para autônomo industrial.

${ }^{10}$ Verso encontrado em Said (2007, p. 42).
} 
o progresso e a modernidade, o País se via as voltas com uma realidade arcaica, eminentemente rural e escravista. No Brasil da virada do século XIX para o XX, nunca as mazelas da sociedade escravista e opressora ficaram tão marcadamente evidentes. Os ventos fortes da República sopravam em direção às luzes de novos tempos havendo os resquícios da sociedade colonial e monárquica de serem enfim eliminados.

A nova Capital serviu como marco divisor do antigo para o moderno, de um poder para o outro, desenhada "a régua e compasso", e essa modernidade almejada, deveria atingir, não só os novos prédios e palácios como também o comportamento, o jeito de viver das pessoas (JULIÃO, 1992). Para isso, foi executado o projeto no âmbito arquitetônico como também a idealização da formação (imposição?) de novos hábitos humanos a circular pela cidade.

O jornal A Folha ${ }^{11}$ de 1904 exibiu o contraste provocado pelo período transitório civilizador que a nova cidade teria e ajudaria a formar! "Bello Horizonte é um meio social novo; a sua população veio de todos os pontos e o conjuncto não póde ter ainda habitos tradicionaes". Este povo, se trabalhado os bons modos, seria "[...] um bom material para ser modelado e servir de exemplo ao Estado".

O jornal literário da novata juventude mineira, Affonso Celso $^{12}$, de 1907, demonstrou a função efetiva de todos os componentes da sociedade da época - essencialmente da mocidade - no sucesso da obra civilizatória da República no Brasil: “os moços não podem mais representar o modesto papel de <<fugazes borboletas do jardim da vida $>>$ ". Na nova concepção social moderna era exigido "o concurso de todos, desde o millionario ate ao misero proletario, do sabio assim como do inculto, desde o homem mais robusto ate a mais fragil donzella, desde o velho encanecido ate o moço cheio de vigor e de esperanças". Era, para o jornal, função da juventude a "guarda da chamma imperecivel da liberdade em seu coração". O jovem da jovem Capital era o berço do novo, do moderno jeito de se viver. Sairiam da penumbra de suas casas, iriam para as ruas e praças. Praticariam esportes.

Cynthia Veiga chama a atenção para a função civilizadora dos novos edifícios, ruas e parques da Capital. O comportamento do povo nos logradouros públicos definiria a composição, ou não, de homens e mulheres de características modernas. Se os habitantes locais desenvolvessem hábitos civilizados nas ruas, tornar-se-iam "referências para as "práticas atrasadas" daqueles marginalizados física e culturalmente da cidade" (VEIGA, 1994, p.461).

\footnotetext{
${ }^{11}$ A Folha. Quarta-feira, 20 de julho de 1904 - O Bom Tom, p.2.

12 Affonso Celso. Domingo, 14 de julho de 1907 - Nosso fim, p.1.
} 
Tarcísio Mauro Vago apresenta indícios da pretendida transformação com a reforma da educação formal republicana. Se no início da cidade o ensino era baseado em escolas isoladas e custeadas pelo Estado, a partir de 1906, o governo de Minas Genais reformaria e o ampliaria em todo o Estado. Ler, escrever e contar, não seriam as únicas finalidades, a escola deveria conduzir a juventude à disciplina, saúde e ordem, mudando seus hábitos, comportamentos e valores.

$\mathrm{O}$ advento desse novo molde escolar tem em vista responder à expectativa de formar aqueles que seriam os cidadãos republicanos - civilizados, de maneiras amaciadas, disciplinados, sadios e trabalhadores ordeiros -, que assim poderiam contribuir para o desejado progresso social. No cerne, como alvo para o qual convergiriam os dispositivos dessa nova cultura escolar, estava o corpo das crianças: a organização da cultura escolar deveria cultivar um corpo belo, forte, saudável, higiênico, ativo, ordeiro, racional, em contraposição àquele considerado feio, fraco, doente, sujo e preguiçoso (VAGO, 1999, p.32).

Em tempo, porém, viu-se que a tarefa não seria fácil. Com a instalação da nova Capital observou-se que a cidade surge sem identidade, “[...] toda a gente que ali frequentava ou chegava: operários, funcionários públicos e muitos oportunistas da sorte transformaram a cidade num emaranhado de povos sem preocupação com a boa convivência ou relações familiares" (VILHENA, 2008, p.40). O sonhado modus vivendi cosmopolita e civilizado, estilo parisiense, não se consolidou como se pretendia. No cotidiano da Belo Horizonte do início do século XX se confundiam o velho e o novo, o antigo e o moderno, o provinciano e o cosmopolita.

O Brasil, diferentemente das outras nações latino-americanas, após a independência, viveu no regime monárquico por 67 anos, de 1822 a 1889. Esse fato pode ter dificultado o processo de transição de Monarquia (ainda com ares de Colônia) para República democrática. Contudo, apesar de ambígua e confusa, principalmente em Belo Horizonte, a pueril República brasileira promoveu mais autonomia e sensação de liberdade de expressão à população. Como expresso no Diario de Minas ${ }^{13}$ de 1913:

[...] si a Republica não é o regimen que desejaram tantos brasileiros; si o paiz ainda não conseguiu o maximo da civilisação desejada, da-nos, pelo menos, a certeza de que somos um povo livre, possuindo todas as autonomias desejáveis, elegendo os nossos dirigentes e criticando sem impecilios os actos governamentaes. Tenhamos fé no futuro; esperemos ainda um pouco e, trabalhando com energia e afinco, havemos de chegar ao fim desejado. A Republica brasileira é muito moça ainda! G.

\footnotetext{
${ }^{13}$ Diário de Minas. Domingo, 16 de novembro de 1913. Chronica Social, p.2.
} 
Outra questão chamou a atenção em Belo Horizonte: teriam os governantes a dignidade de prover a cidade de infraestrutura básica à população, ao nível das modernas e civilizadas como conjecturavam os idealizadores?

No expediente de 25 de março de 1923, A Gazeta expôs, regado à ironia e sarcasmo, angústias dos habitantes de Belo Horizonte quanto às prioridades urbanísticas e desconfianças quanto à administração do erário público: ajardinamento das praças ou redes de esgotos?

Jardins, jardins,...exgotto não!

Bello Horizonte resente-se de muita cousa para ser uma capital modelo, mas muita cousa mesmo.

Mas, entre estas cousas, resaltam logo duas importantes: esgoto e calçamento. Bello Horizonte não será, de forma alguma, uma capital hygienicamente perfeita, enquanto a poeira conspirar contra os pulmões de seus habitantes e enquanto as redes de esgotto não se mostrarem por todos os recantos da cidade. Mas as administrações municipais se succedem e esses dois problemas não são resolvidos. Por quê? [...] Ora, não acreditamos que os nossos administradores esperem um passe de mágica, que amanhã ou depois dê a Prefeitura os milhares de contos necessários para a execução de taes obras. [...] Não seria muito mais justo e rasoavel que a Prefeitura empregasse o dinheiro que vai gastar em taes ajardinamentos em exttender a rêde de esgottos a uma rua qualquer ou, até mesmo, a dois ou três quarteirões somente.

O lucro para a Capital seria, estamos convencidos, muito maior. Salvo si a Prefeitura, dando-nos jardins e privando-nos do esgotto, tem em mira encobrir com o perfume das flores o máo cheiro das ruas... Si assim é, damos as mãos à palmatória... ${ }^{14}$

As vestimentas preferidas da sociedade belo-horizontina do início do século XX são, também, um viés a ser observado, visto que foi um item definidor da modernidade brasileira. A moda seguida foi, via de regra, copiada da francesa ${ }^{15}$. Essa importação produziu figuras consideradas esdrúxulas e estranhamento da população mais avessa às mudanças sociais. $A$ Gazeta de 1914 demonstrou aflição com a imagem pública da mocidade local, prevendo um futuro catastrófico.

A moda domina o mundo desde os primeiros surtos de civilização. Mas nos tempos modernos attingiu ella o seu mais alto gráo de prepotencia para com os pobres mortaes. O seu capricho é de tal forma que tem masculinizado a mulher e efeminizado o homem. Não raro vemos as senhoritas de saias sobre o corpo apenas guarnecido por um collete e finíssima camiseta, tornando-as, com o conjuncto do calçado e do chapéo exquisitos, muito semelhantes aos rapazinhos tolos de casaco abotoado. Por outro lado os jovens, que se dizem smarts, escanonham-se a valer, raspam os bigodes, empoam-se, perfumamse, calçam botinas de cano alto, usam chapéos de laço de cores berrantes...

${ }^{14}$ A Gazeta. 25 de maio de 1923: Jardins, jardins,...exgotto não!, p.2.

15 "O francesismo, que já era chique nos tempos da monarquia, continua a imperar na República" (COSTA e SCHWARCZ, 2007, p.69). 
E não pensam esses pobres inexpertos na vida, que todo esse martyrio não passa de mundanidades doentias que se confundirão, mais tarde, com o pó universal... ${ }^{16}$

Na Chronica Social do jornal Diário de Minas de 1924 percebemos o olhar equivocado das senhoras do local para com a moda europeia. Na ânsia de se postarem modernamente acabavam por se vestir com adereços dignos das francesas de reputação duvidosa: brasileiras deslumbradas, porém chics.

A minha ultima chronica foi um commentario ao descritério com que no Brasil muitas mulheres que se julgam chics copiam modas européas, na convicção rastaquera de que não é possível ser-se elegante sem se vestir pelos figurinos parisienses. E mostrei que a preocupação de imitar Paris chega ao ponto de haver senhoras casadas e honestas, em nosso paiz que se vestem como, na europa se vestem as <cocottes>.

Uma nossa patrícia teve a gentileza de mandar-me palavras de applausos pela maneira por que procuro "combater um costume que so serve para nos diminuir perante os outros povos" [...]. ${ }^{17}$

Enfim, não é dizer que a cidade não deu certo, mas que uma cidade vai se construindo em meio a tensões e ambiguidades. Uma nova sociedade é marcada por fatores que a prancheta dos idealizadores não tem como prever ou mesmo os elimina. E para entender a dinâmica urbana recorremos a Michel de Certeau.

[...] se, no discurso, a cidade serve de baliza ou marco totalizador e quase mítico para as estratégias sócio-econômicas e políticas, a vida urbana deixa sempre mais remontar àquilo que o projeto urbanístico dela excluía. A linguagem do poder "se urbaniza", mas a cidade se vê entregue a movimentos contraditórios que se compensam e se combinam fora do poder panóptico ${ }^{18}$. A Cidade se torna o tema dominante dos legendários políticos, mas não é mais um campo de operações programadas e controladas. Sob os discursos que a ideologizam, proliferam as astúcias e as combinações de poderes sem identidade, legível, sem tomadas apreensíveis, sem transparência racional - impossíveis de gerir (CERTEAU, 1994, p.174).

Numa cidade planejada como Belo Horizonte, para analisá-la, talvez, possamos ir além da fala de Michel de Certeau (1994). As estratégias de gerenciamento social, político e econômico, por certo, seriam de maior complexidade do que o suposto e poderiam sair do controle de quem as idealizara, com o passar dos anos. Veriano (2001) pondera, dizendo que esta cidade, como todas as cidades utópicas, seria regida pelas leis de uma simples e estrita geometria, o que era de difícil assimilação para aquele povo que aqui se instalara.

\footnotetext{
${ }^{16}$ A Gazeta. Terça-feira, 15 de setembro de 1914. Espirito vadio, p.1.

${ }^{17}$ Diário de Minas. Terça-feira, 25 de março de 1924. Chronica Social, p.2.

${ }^{18}$ O Panóptico funciona como uma espécie de laboratório de poder. Graças a seus mecanismos de observação, ganha em eficácia e em capacidade de penetração no comportamento dos homens; um aumento de saber vem se implantar em todas as frentes do poder, descobrindo objetos que devem ser conhecidos em todas as superfícies onde este se exerça (FOUCAULT, 2005).
} 
Não cabe concluir se Belo Horizonte desenvolveu como planejada, porém é razoável inferir que a ambiguidade foi marca latente no desenvolvimento dessa cidade. Simultaneamente, ela foi moderna e arcaica ao mesmo tempo e espaço. A ideia da cidade alinhavada na geometria dos engenheiros seguiu-se numa inevitável frustração, uma vez que, segundo Lara (1998, p.96), “[...] nem o controle estatal seria capaz de realizar no espaço urbano o sonho republicano, a Poeirópolis, revelou-se uma cidade vazia, desproporcional e dispersa".

\section{Considerações finais}

Sem a intenção de esgotar a discussão, o que se nota é que todos os movimentos pensados para a nova capital de Minas Gerais, aparentemente, seguiram propósitos determinados por um novo modus vivendi influenciado pela modernidade europeia. Desde a procura e escolha do local de sua construção havia finalidades políticas, notadamente no tocante a nova estrutura política do estado, a República, proclamada em 1889. O temor do possível retorno da monarquia exigia demonstrar que esta possibilidade não existia, daí o simbolismo no surgimento da cidade que refletiria o moderno, o civilizado, o urbano, em contraposição à antiga e atrasada Ouro Preto monarquista.

Pelos periódicos e autores consultados, percebeu-se que não havia intuito, na mudança de endereço da capital, de se negligenciar o orgulho do povo mineiro, depositado nas ideias libertárias dos personagens independentistas da Ouro Preto oitocentista. Se em princípio, no reino ideológico o objetivo foi sepultar a antiga Ouro Preto embaixo da arrojada Belo Horizonte, na prática, o belo-horizontino que se formava, orgulhou-se da grandiosa nova capital sem desmerecer o passado, a tradição e a história da antiga. Ambas desenvolveram significados próprios: a moderna poderia conviver com a tradição e a glória da velha capital. Por fim, como bem definiu o jornal A Faísca ${ }^{19}$, em 1916: “Olhemos para o futuro, Bello Horizonte honrará Ouro Preto".

Obviamente, determinar mudanças tão drásticas no hábito de vida das pessoas soava ingênuo. Possivelmente, como mostramos, observando a confusão que a implantação da nova capital trazia, é que o poeta Carlos Drummond de Andrade, mineiro do interior e morador da nova cidade, sintetizou em apenas um verso a "roupa" de uma cidade moderna tentando "vestir" num sujeito interiorano: "No elevador penso na roça, na roça penso no elevador ${ }^{20}$.

\footnotetext{
${ }^{19}$ A Faísca. Terça-feira, 12 de dezembro de 1916: A nova capital de Minas, p.1.

${ }^{20}$ Verso encontrado em Said (2007, p. 42).
} 
Pode-se afirmar que a Belo Horizonte da virada do século XIX para o XX, trazia impregnada as mazelas da sociedade escravocrata e opressora que ficaram tão marcadamente evidentes até a segunda metade do Século XIX no Brasil. Entretanto, havia um esforço na mudança de direção da política brasileira, onde a recém instalada República conduziria a nação na direção oposta da Monarquia, uma forma de governo que lembrava o Brasil "colônia" de Portugal. Essa ideia de mudança podia ser notada no projeto arquitetônico da nova cidade, um conceito concreto, como também na imposição de novos hábitos de vida, ligado ao aspecto comportamental do suposto novo jovem cidadão moderno.

Forjar o belo-horizontino não seria tarefa fácil, esse processo exigiria, segundo as fontes, o envolvimento de todos, “[...] desde o homem mais robusto ate a mais fragil donzella, desde o velho encanecido ate o moço cheio de vigor e de esperanças". Talvez, por isso, estabelecer o uso da moda parisiense criaria equívocos advindos da comunicação ruim. A belo-horizontina, na ânsia de se portar moderna, chic, acabava por se vestir como uma francesa de precária reputação social. O sonhado modus vivendi cosmopolita e civilizado, estilo parisiense, não se consolidou como se pretendia. No cotidiano da Belo Horizonte do início do século XX se confundiam o velho e o novo, o antigo e o moderno, o provinciano e o cosmopolita. Enfim, constitui-se um cenário de tensão social, surgido da convivência imposta entre o tradicional e o moderno.

Imaginar e projetar uma cidade aos moldes europeus, como imaginaram seus governantes, não se constituíam nos maiores problemas, a questão principal foi não haver provido a população que nela moraria de infraestrutura básica. Daí então, ao invés de uma cidade moderna e civilizada, os jornais transmitiam características de atraso e desleixo, demonstrando uma cidade que se ressentia "[...] de muita cousa para ser uma capital modelo, mas muita cousa mesmo",21.

Não é intenção afirmar que a cidade não deu certo, como previsto. Mas é concluir que se constituiu em meio a tensões e ambiguidades. O cidadão que se forjou é marcado por características que os idealizadores não conjecturaram. As estratégias de gerenciamento social, político e econômico, por certo, foram de maior complexidade do que o suposto e poderiam sair do controle de quem as idealizara, com o passar dos anos.

${ }^{21}$ A Gazeta. 25 de maio de 1923: Jardins, jardins,...exgotto não!, p.2. 


\section{Fontes}

A Faísca. Terça-feira, 12 de dezembro de 1916: A nova capital de Minas, p.1.

A Folha. Quarta-feira, 20 de julho de 1904 - O Bom Tom, p.2.

A Gazeta. Terça-feira, 15 de setembro de 1914. Espirito vadio, p.1.

A Gazeta. 25 de maio de 1923: Jardins, jardins,...exgotto não!, p.2.

A Gazeta. Segunda-feira, 28 de maio de 1923: Aspectos da cidade, p.2.

Annuario de Minas Geraes. Bello Horizonte, 1906, p.131.

Bello Horizonte. Domingo, 2 de fevereiro de 1896. Traços historicos e descriptivos de Bello Horizonte V, p.1.

CELSO, Affonso. Domingo, 14 de julho de 1907 - Nosso fim, p.1.

Diário de Minas. Domingo, 16 de novembro de 1913. Chronica Social, p.2.

Diário de Minas. Terça-feira, 25 de março de 1924. Chronica Social, p.2.

\section{Referências bibliográficas}

BARROS, José D’Assunção. História, Espaço e Tempo: interações necessárias. Varia História, Belo Horizonte, vol. 22, nº 36: p.460-475, 2006.

CERTEAU, Michel de. A invenção do cotidiano 1: artes de fazer. Petrópolis: Vozes, 1994.

COSTA, Angela Marques da; SCHWARCZ, Lilia Moritz. 1890-1914: no tempo das certezas.

São Paulo: Companhia das Letras, 2007.

FOUCAULT, Michel. Vigiar e Punir: nascimento da prisão. $3^{\circ}$ ed. Petrópolis: Vozes, 2005.

GIDDENS, Antony. As consequências da modernidade. São Paulo: Unesp, 1991.

JULIÃO, Letícia. Belo Horizonte: itinerários da cidade moderna (1891-1920). Dissertação (Mestrado em Ciência Política) - Faculdade de Filosofia e Ciências Humanas, Universidade Federal de Minas Gerais. Belo Horizonte, 1992.

LARA, Fernando. Geometria naviana: transformações do espaço Belo-horizontino. Revista Belo Horizonte, v.2, p.95-104, 1998.

OLIVEN, Ruben George. Cultura e modernidade no Brasil. São Paulo em Perspectiva, v.15, n. 2, 2001.

PASSOS, Daniela. A formação do espaço urbano da cidade de Belo Horizonte: um estudo de caso à luz de comparações com as cidades de São Paulo e Rio de Janeiro. Mediações, Londrina, v. 21, n. 2, p. 332-358, 2016.

PIMENTEL, Thais Velloso Cougo. A Torre Kubitschek: trajetória de um projeto em 30 anos de Brasil. Dissertação (Mestrado em História) - Instituto de Filosofia e Ciências Humanas, Universidade Estadual de Campinas. Campinas, 1989.

RODRIGUES, Marilita Aparecida Arantes. Constituição e enraizamento do esporte na cidade: Uma prática moderna de lazer na cultura urbana de Belo Horizonte (18941920). Tese (Doutorado em História) - Faculdade de Filosofia e Ciências Humanas, Universidade Federal de Minas Gerais. Belo Horizonte, 2006.

RODRIGUES, Danielle Uchôa Alonso. Cidade real e cidade imaginária: a criação de Belo Horizontes (1895-1910). Dissertação (Mestrado em Sociologia) - Programa de PósGraduação em Sociologia - Faculdade de Filosofia, Letras e Ciências Humanas, Universidade de São Paulo. São Paulo, 2016.

SAID, Roberto Alexandre do Carmo. Quase biografia: poesia e pensamento em Drummond. Tese (Doutorado em Letras) - Faculdade de Letras - Universidade Federal de Minas Gerias. Belo Horizonte, 2007. 
SENRA, Marcia. A cidade moderna: história, memória e literatura - Paris, Belo-Horizonte. Revista Univap, São José dos Campos, v.17, n. 29, p. 62-79, 2011.

SEVCENKO, Nicolau. Orfeu extático na metrópole: São Paulo, sociedade e cultura nos frementes anos 20. São Paulo: Companhia das Letras, 1992.

SILVEIRA, Ana Carolina Costa; SILVA, Regina Helena Alves da. Os espaços de lazer na cidade: a política urbana de Belo Horizonte. Licere, Belo Horizonte, v.13, n.3, p.1-42, 2010.

SIMÃO, Fábio Luiz Rigueira. Tradição e modernidade na construção da nova capital mineira: o Padre Francisco Martins Dias e os "Traços Históricos e Descriptivos de Bello Horizonte". Revista Eletrônica Cadernos de História, v.6, ano 3, n.2, p.117-136, 2008. Disponível em: http://www.ichs.ufop.br/cadernosdehistoria. Acesso em: 10 ago. 2013.

VAGO, Tarcísio Mauro. Início e fim do século XX: maneiras de fazer educação física na escola. Cad. CEDES, Campinas, v. 19, n. 48, ago. 1999. Disponível em: http://www.scielo.br/scielo.php?script=sci_arttext\&pid=S010132621999000100003\&lng=pt \&nrm=iso. Acesso em: 28 mar. 2012.

VEIGA, Cynthia Greive. Cidadania e educação na trama da cidade: a construção de Belo Horizonte em fins do século XIX. Tese (Doutorado em História) Instituto de Filosofia e Ciências Humanas, Universidade Estadual de Campinas. Campinas, 1994.

VERIANO, Carlos Evangelista. Belo Horizonte: cidade e política - 1897-1920. Dissertação (Mestrado em História) Instituto de Filosofia e Ciências Humanas, Universidade Estadual de Campinas. Campinas, 2001.

VILHENA, Kellen Nogueira. Entre "sãns expansões do espírito" e "sarrilhos dos diabos": lazer, divertimento e vadiagem nas representações da imprensa em Belo Horizonte (1895 1922). Dissertação (Mestrado em Lazer) - Programa de Pós-Graduação Interdisciplinar em Estudos do Lazer, Universidade Federal de Minas Gerais. Belo Horizonte, 2008. 